\title{
Behavioral adaptation to climate change in wildfire-prone forests
}

\author{
Matthew Hamilton $^{1 *}$ | Alexandra Paige Fischer ${ }^{1}$ | Seth D. Guikema ${ }^{2}$ | Gretchen Keppel-Aleks ${ }^{3}$
}

${ }^{1}$ School for Environment and Sustainability,

University of Michigan, Ann Arbor, Michigan

${ }^{2}$ Industrial and Operations Engineering, University of Michigan, Ann Arbor, Michigan

${ }^{3}$ Climate and Space Sciences and Engineering, University of Michigan, Ann Arbor, Michigan

Correspondence

Alexandra Paige Fischer, School for Environment and Sustainability, University of Michigan,

440 Church Street, Ann Arbor, MI 48109.

Email: apfisch@umich.edu

Funding information

MCubed, University of Michigan

Edited by Lisa Dilling, Domain Editor, and Mike Hulme, Editor-in-Chief

The link between climate change and increased wildfire risk highlights the need for adaptation in wildfire-prone landscapes. While extensive research has focused on adaptation at the levels of communities, policies, and governance systems, there is limited understanding of adaptation at the level of individual behavioral responses. Individuals not only directly experience the adverse effects of wildfires but also shape their own exposure to wildfire through risk mitigation practices. Without knowledge of whether these behaviors are adaptive, decision makers are limited in their ability to design and assess climate change adaptation policies that improve outcomes in wildfire-prone regions. Likewise, greater understanding of the processes by which behavioral adaptation occurs can improve theories of behavior under risk, and specifically how psychological and social factors mediate the effects of hazard conditions on behavior. This paper reviews scholarship on biophysical, psychological, and social factors that shape behavioral adaptation to climate change in wildfire-prone forests. Our review highlights opportunities to improve theory and assist risk mitigation policy interventions by focusing greater attention on dynamic feedbacks involving hazards, behavior, and outcomes, as well as accounting for variation in behavior and wildfire hazard conditions.

This article is categorized under:

Vulnerability and Adaptation to Climate Change > Institutions for Adaptation

\section{KEYWORDS}

behavioral adaptation, human-environment feedbacks, individuals, wildfire

\section{1 | INTRODUCTION}

Linkages between climate and wildfire have spurred research on how projected climate conditions may alter wildfire intensity, frequency, and seasonality (Harris, Remenyi, Williamson, Bindoff, \& Bowman, 2016; Marlon et al., 2009; Stavros, McKenzie, \& Larkin, 2014; Westerling et al., 2011). Although wildfire is a key ecological process that has historically maintained forests in many ecosystems where people live (Bowman et al., 2011), the pace and magnitude of changing wildfire regimes presents a significant challenge to societies (Millar \& Stephenson, 2015). A core theme in research on human dimensions of wildfire is the need for adaptation to accommodate or anticipate changing hazard conditions (Fischer, Spies, et al., 2016; Spies et al., 2017). Adaptation may encompass adjustment of fire response policies, approaches for management of fire-prone public lands as well as large scale private lands used for timber production, regulations for residential zoning and home construction, and practices for maintaining private properties in light of changing wildfire hazard conditions (Calkin, Thompson, \& Finney, 2015; McCaffrey, Stidham, Toman, \& Shindler, 2011; NielsenPincus et al., 2010; North et al., 2015; Spittlehouse, 2005). These diverse veins of research reflect the multilevel adaptation challenges presented by wildfire risk (Fischer, Spies, et al., 2016).

*Present address: School of Environment and Natural Resources, The Ohio State University, Columbus, Ohio. 
In many ways, individual-level behavioral responses to wildfire risk are central to adaptation outcomes. Adverse impacts from wildfires are incurred at the individual-level, by way of threats to safety and health, homes and other financial assets, timber and other natural resources, and cultural values such as attachment to place (Brenkert-Smith, Dickinson, Champ, \& Flores, 2013; Fischer, Kline, Ager, Charnley, \& Olsen, 2014; K. C. Nelson, Monroe, \& Johnson, 2005; Paveglio, Carroll, \& Jakes, 2010). Additionally, individual behaviors can directly shape hazard conditions on residential lots as well as large private forested properties (Fischer et al., 2014; Olsen, Kline, Ager, Olsen, \& Short, 2017; Syphard, Brennan, \& Keeley, 2014), which in turn influence wildfire behavior and associated adverse impacts. Policies that aim to help residents and forest owners coexist with wildfire can benefit from greater understanding of the drivers and outcomes of wildfire risk mitigation behavior (Moritz et al., 2014), which can serve to both help identify adaptive behavioral responses that best fit local social and ecological contexts as well as diagnose and overcome barriers to adaptation. Indeed, greater attention to the dynamics of individuallevel behavioral adaptation to changing wildfire conditions echoes calls for improving understanding of behavioral adaptation to climate change impacts more generally (Clayton et al., 2015; Swim et al., 2009), which has received limited attention relative to adaptation at levels of communities, policies, and governance systems (Berrang-Ford, Ford, \& Paterson, 2011).

This review draws upon diverse disciplinary perspectives to first identify the core components that shape behavioral adaptation to climate change, which is a dynamic process that features human-environment feedbacks. Correspondingly, core components of behavioral adaptation include biophysical drivers of behavior, the mediating effects of affective, cognitive, and social processes on behavioral responses, behavior, and the outcomes of behavior in light of ongoing environmental change. For each component, we review the state of knowledge about specific sets of factors and processes relevant to the wildfire context (e.g., for biophysical drivers, specific factors include changing wildfire frequency). Despite the lack of studies that account for temporally dynamic feedbacks, or that undertake analysis of factors that span all core components of adaptation, our review reveals substantial knowledge about relationships among subsets of factors (e.g., the relationship between personal responsibility and propensity to undertake risk mitigation; W. E. Martin, Martin, \& Kent, 2009), which provides a strong foundation for comprehensive analysis of behavioral adaptation to climate change in wildfire-prone forests. To encourage such efforts, we synthesize the core components of our review in a framework designed to facilitate analysis of behavioral adaptation to changing wildfire hazard conditions as a dynamic process. We conclude by reflecting on current understanding of behavioral adaptation in wildfire-prone systems while proposing an agenda for future research.

\section{I KEY CONCEPTS AND COMPONENTS OF BEHAVIORAL ADAPTATION TO CLIMATE CHANGE}

The concept of adaptation has been used in different ways in reference to climate change (Birkmann, 2011; D. R. Nelson, Adger, \& Brown, 2007; Smit \& Wandel, 2006). In evolutionary biology, the term refers to the process by which certain traits become more prevalent because they improve the likelihood of survival and reproduction under new environmental conditions (Dobzhansky, 1968). In the latter half of the twentieth century, anthropologists and geographers drew upon similarities between biological and cultural evolution to better understand how behavioral traits (and other manifestations of culture) adapt to changing conditions, which included not only the biophysical environment, but also economic forces and large-scale demographic change (Denevan, 1983; Head, 2009; Watts, 1983). In parallel, research on hazards conceptualized adaptation as one potential response to environmental change, along with coping and recovering (Blaikie, Cannon, Davis, \& Wisner, 2014; Burton, 1993; Hewitt, 1997). Work in this field has largely focused on adaptive capacity, and its determinants, as a precondition for adaptation rather than the process of adaptation itself (Adger, Kelly, \& Ninh, 2012; Turner et al., 2003). The emergence of climate change as a global policy issue resulted in an alternative conceptualization of adaptation as a policy goal that is complementary to mitigation (Orlove, 2005). In the policy realm, adaptation is regarded more commonly as an outcome rather than a process (Dovers \& Hezri, 2010; Dupuis \& Biesbroek, 2013). Correspondingly, conceptualization of adaptations as options or measures focuses on the potential outcomes of policy instruments designed to address features of environmental change.

The Intergovernmental Panel on Climate Change (IPCC) defines adaptation as "adjustment in natural or human systems in response to actual or expected climatic stimuli or their effects, which moderates harm or exploits beneficial opportunities" (Mach, Planton, \& von Stechow, 2014, p. 117). Implicit in this definition are two criteria for adaptive responses: they must arise in response to the effects of climate change and they must result in beneficial outcomes, such as reducing adverse effects of climate change. An individual's behavior is adaptive (Box 1) if it helps the individual better take advantage of opportunities - or respond to challenges - that result from environmental conditions associated with climate change. These behaviors will continue to be adaptive until future environmental conditions compel further adjustments. Consequently, characteristics of an adaptive behavior are the legacy of conditions of environmental change. By contrast, the benefits associated with a behavior may provide indication of the characteristics of adaptive behavior in the future (Sober, 1993). The degree to 


\section{BOX 1}

KEY TERMINOLOGY ON BEHAVIORAL ADAPTATION TO CLIMATE CHANGE

Adaptive behavior: A behavior that contributes to beneficial outcomes for individuals exposed to the effects of climate change.

Behavioral action: A practice, measure, or activity undertaken by an individual in response to climate change impacts. Behavioral strategy: An individual's approach for responding to climate change. An overall strategy can be decomposed into tendencies (e.g., more proactive vs. more reactive).

Behavioral adaptation: The process by which certain features of behavioral actions or strategies become more prevalent among individuals because those features enable better outcomes under changing climatic conditions.

which behavior is adaptive depends in part upon the time scale at which behavior-environment outcomes are considered. A behavior that is less beneficial in the short term may nevertheless prove adaptive over longer periods of time and vice versa. For this reason, assessment of the adaptiveness of a behavior depends upon the period of time over which its outcomes are evaluated. Importantly, individual-level adaptive behaviors need not result in public benefits although they sometimes do (Tompkins \& Eakin, 2012). In this regard, the metric of evaluation of adaptiveness depends upon the level of analysis. Just as the adaptiveness of community- or system-level responses to environmental change may be evaluated based on outcomes at those respective levels (D. R. Nelson et al., 2007), individual-level outcomes determine the adaptiveness of individual-level behaviors.

Of particular relevance to adaptation at the individual-level are the psychological and social processes that influence how individuals respond to environmental change, which they may experience directly or indirectly. The socio-cognitive Model of Private Proactive Adaptation to Climate Change (MPPACC) accounts for many of these processes, including risk perception and risk experience appraisal (Grothmann \& Patt, 2005). Applications of MPPACC have demonstrated the importance of affective, cognitive, and social processes, which better predicted risk mitigation behavior than a socio-economic model (Grothmann \& Patt, 2005). Likewise, factors such as perceived self-efficacy, response efficacy, and risk perception have been shown to be strong predictors of behavioral response to climate change impacts on agricultural productivity (Niles, Brown, \& Dynes, 2016; Truelove, Carrico, \& Thabrew, 2015; Wheeler, Zuo, \& Bjornlund, 2013). Studies that similarly document significant relationships between psychological and social factors and individual-level response environmental change highlight the importance of these factors in understanding behavioral adaptation to climate change across a range of hazards contexts (for recent reviews, see Clayton et al., 2015; Reser \& Swim, 2011).

Individuals respond to climate change impacts through a wide range of actions and strategies, and several typologies have been proposed for classifying these behavioral responses. One approach focuses on the timing of response relative to the onset of hazard events. Proactive behaviors, which involve preparation and planning, and typically account for potential future conditions, stand in contrast to more reactive behaviors undertaken in response to immediate motivations (Berrang-Ford et al., 2011; Fankhauser, Smith, \& Tol, 1999). The distinction between autonomous and planned adaptation reflects the degree to which responses to environmental change are intentional. While autonomous behavior involves a spontaneous response, planning involves strategic and deliberate decision-making (Fankhauser et al., 1999; Smit, Burton, Klein, \& Street, 1999). Another typology focuses on the degree to which responses are transformative rather than incremental (Kates, Travis, \& Wilbanks, 2012; Park et al., 2012; Pelling, O'Brien, \& Matyas, 2015). A defining feature of transformative responses is their application of novel and innovative approaches, which may be especially important when the magnitude of environmental change challenges the appropriateness of conventional risk response measures that would constitute a strategy of incremental adjustments (Kates et al., 2012). Another dimension along which behaviors vary is the degree to which they spread risk. Confronted with uncertainty about the most effective response given changing environmental conditions, individuals may hedge their bets through diversification, for example, of crop varieties (Smit \& Skinner, 2002), or may concentrate their investments. Adaptation scholars also characterize behaviors depending on whether, or the degree to which, they involve collective action. Certain responses to changing environmental conditions require a critical mass of individuals investing in the same action, such as building a sea wall (Mendelsohn, 2000), while other activities are effective regardless of whether they are jointly undertaken by others.

Research on individual behavioral adaptation, including applications of the typologies profiled above, as well as analytical frameworks such as MPPACC, generally focuses on predicting behavioral response to risk in one time step, rather than analyzing a sequence of responses as part of a dynamic process. This approach relies upon prior knowledge or assumptions about the adaptiveness of behaviors, rather than measures of the outcomes of behaviors in terms of their suitability to changing 
environmental conditions. An alternative approach involves evaluation of adaptation as a dynamic process, in which individuals modify behaviors based on cues about their effectiveness in light of changing environmental conditions. This perspective is central to the concept of adaptation pathways (Fazey et al., 2016; Haasnoot, Kwakkel, Walker, \& ter Maat, 2013; Wise et al., 2014; Fischer, 2018), which accounts for the possibility that responses to environmental change may not be adaptive. Although the pathways approach has primarily been applied at the community level, its focus on feedbacks as a core feature of adaptation is relevant to analysis of causal linkages between behavior and the outcomes of environmental change.

Applying this temporal perspective to the sets of factors profiled above yields a basic framework of behavioral adaptation to climate change (Figure 1). In this framework, adaptation is conceptualized as a process by which hazard conditions and their outcomes shape individual behaviors via mediating effects of psychological (e.g., affective, cognitive) and social processes. In turn, behaviors, jointly with climatic change, affects hazard conditions. The cyclical arrangement of these core components of the process of behavioral adaptation facilitates iterative evaluation of behavioral change over time (e.g., from one growing season to the next).

The specific drivers, mediating processes, behaviors, and outcomes most relevant for evaluation of behavioral adaptation will depend upon the study system. In subsequent sections we identify and discuss the relationships among key factors that shape behavioral adaptation to climate change in wildfire-prone forests.

\section{I WILDFIRE-PRONE FORESTS AS AN IDEAL CASE FOR EXAMINING BEHAVIORAL ADAPTATION TO CLIMATE CHANGE}

This review focuses on individual behavioral adaptation in ecosystems characterized by forests historically maintained by wildfire (i.e., fire-adapted forests), which are located throughout mid-latitude regions with temperate and Mediterranean climates as well as the higher-latitude boreal biome (Bowman et al., 2011). These forests comprise an ideal study system for investigating human behavioral adaptation to climate change for several reasons. First, the dynamics of wildfire events are largely shaped by weather patterns, which are influenced by long-term climate trends. At regional scales, wildfire intensity depends upon factors such as drought and wind speed (Macias Fauria, Michaletz, \& Johnson, 2011), while more local-level factors include the abundance and distribution of flammable vegetation, which are influenced in part by precipitation (Abatzoglou \& Kolden, 2013; Harris et al., 2016; Moritz et al., 2014; Westerling et al., 2011) and other weather-related variables, such as lightning activity (Preisler, Brillinger, Burgan, \& Benoit, 2004; Westerling \& Bryant, 2007). Models of wildfire risk under future climate scenarios suggest increasing fire probability in temperate coniferous forests in the near-term (2010-2039) and in temperate coniferous, broadleaf, and mixed forests in the long-term (2070-2099) (Moritz et al., 2012; Price et al., 2013; Yue et al., 2015). These trends may amplify risks in forests throughout the United States, Canada, Australia, and the Mediterranean, where changing fire regimes have resulted in significant loss of life and economic impacts (Bowman et al., 2011; Chapin et al., 2008; Moritz et al., 2014; Stephens et al., 2014).

Additionally, forest management practices and other forms of human behavior influence the degree to which climatic changes affect wildfire risk. For example, although some types of pine forests and dry mixed conifer forests throughout the western United States historically experienced frequent low-intensity wildfires that cleared understory vegetation (Stephens \& Collins, 2004; Veblen, Kitzberger, \& Donnegan, 2000), these forests now experience high-intensity "megafires" (Millar \& Stephenson, 2015) fueled by high densities of flammable vegetation that accumulated as a result of wildfire suppression during the twentieth century (Fischer, Spies, et al., 2016; North et al., 2015). In addition to large-scale policies, wildfire risk also depends on forest management practices such as thinning of vegetation, prescribed burning, and planting of fire-adapted trees (Fischer, 2011; Gan, Jarrett, \& Gaither, 2015; Williams, 2013). Because fires increasingly burn across large regions of forested landscapes, risk may also be influenced by social behaviors, such as joint action among neighbors to conduct fuels treatments that span property boundaries (Ager, Day, Finney, Vance-Borland, \& Vaillant, 2014; Busby, Albers, \& Montgomery, 2012; Fischer \& Charnley, 2012).

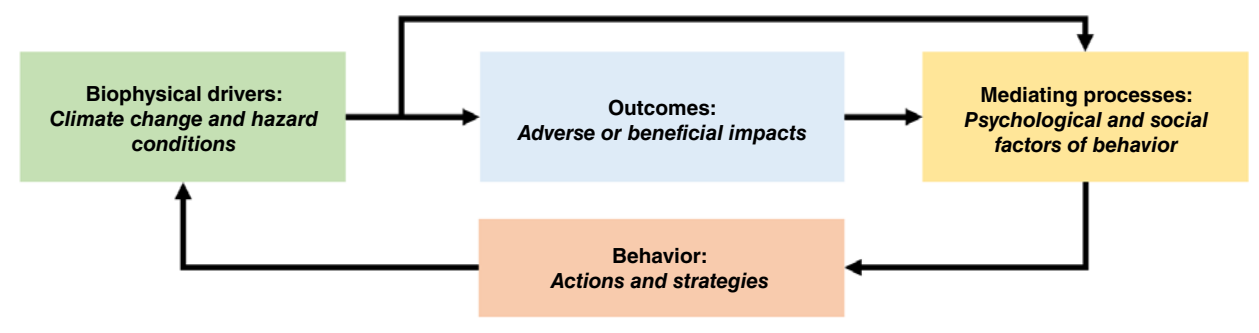

FIGURE 1 Components of a framework of behavioral adaptation to climate change in settings where climate and behaviors jointly shape hazard conditions 
In the United States, the wildland-urban interface, where human settlements exist within fire-prone forests, expanded by over 50\% from 1970 to 2000 (Theobald \& Romme, 2007). Policies that aim to reduce wildfire risk must not only account for this population growth, but also accompanying changes in values and goals for land management (Collins, 2005; Stavros et al., 2014). These demographic trends underscore the importance of improving understanding of the dynamics of behavioral adaptation in wildfire-prone forests, which is not just of academic interest, but also highly relevant for policy interventions designed to reduce wildfire risk.

\section{4 | BIOPHYSICAL DRIVERS OF BEHAVIORAL ADAPTATION}

While countless specific characteristics of changing wildfire hazard conditions influence behavioral adaptation, our review highlights four general attributes, which together describe fundamental features of the changing environment to which people adapt through behavioral adjustments.

\section{1 | Pace of changing hazard conditions}

Wildfire hazard conditions may change rapidly or gradually. For example, in the western United States, where many wildfireprone forests are located, the average annual temperature has risen approximately $1^{\circ} \mathrm{C}$ since 1970 , roughly twice the pace of the global average (Tebaldi, Adams-Smith, \& Heller, 2012). Within this same region of the United States, models indicate accelerating depletion of mountain snowpack, declining fuel moisture, and lengthening of the fire season under a range of 21st century climate scenarios (Gergel, Nijssen, Abatzoglou, Lettenmaier, \& Stumbaugh, 2017). While these conditions will directly affect wildfire behavior, they will also restrict the periods of time each year when it is possible to reduce flammable vegetation through practices such as understory burns (Quinn-Davidson \& Varner, 2012), which further increases hazard conditions. Although such trends may prompt heightened awareness of the need for action (reflected in calls to increase the "pace and scale" of fuels treatment, e.g., North, Collins, \& Stephens, 2012), people may face greater uncertainty about the most effective responses to rapid environmental change (Polasky, Carpenter, Folke, \& Keeler, 2011). Gradual change, although more difficult to perceive and more likely to lead to acceptance of a "new normal," may provide greater opportunities for learning about the causes and implications of new wildfire risk conditions. In some cases, individuals may not perceive that they are at heightened risk but are aware of new conditions they might experience at some point in the future. Under these conditions, anticipatory behavioral adjustments may serve to mitigate future risks or better prepare for opportunities (Tschakert \& Dietrich, 2010).

\section{2 | Changing wildfire intensity}

Climate change may result in modest effects on environmental conditions or may substantially reconfigure natural systems with significant consequences. In some cases, even moderate changes can alter system dynamics in ways that result in a shift from one state to another (Holling, 1973; Walker, Holling, Carpenter, \& Kinzig, 2004). In temperate forests, higher temperatures and lengthier droughts provide the conditions for "megafires" (Millar \& Stephenson, 2015). In the dry interior western region of the United States, forested ecosystems now experience high-intensity wildfires, which mark a shift from the historical high-frequency low-intensity fire regime (Williams, 2013). In these ecosystems, uncontrollable wildfires challenge the efficacy of traditional wildfire suppression approaches, and has sparked interest in alternative strategies, such as reduction of flammable vegetation at the landscape level through prescribed burns.

\section{3 | Changing wildfire frequency}

Changing climatic conditions may alter wildfire return intervals. The implications of increasingly frequent disturbance events depend in part on their intensity as well as the sensitivity of the human populations affected. For example, although frequent but low-intensity wildfire is a natural ecological process in many temperate forests, suppression of fires has resulted in extensive accumulation of flammable fuels across large forested regions (Fischer, Spies, et al., 2016; North et al., 2015). Seasonal weather patterns associated with climate change now provide the conditions for large-scale uncontrollable wildfires (Millar \& Stephenson, 2015). As a result, in many temperate forests where human population growth has prompted efforts to suppress all wildfires, the frequency of low-intensity fires has decreased, but the frequency of high-intensity fires has increased. When extreme events occur frequently and affect vulnerable populations, individuals may have insufficient time or resources to prepare for subsequent events (Chambers, 1989; Kasperson et al., 1988). However, increasingly frequent disturbance events may also serve as cues-to-action and thereby provide impetus for innovative behavioral responses to environmental change (McCaffrey \& Kumagai, 2007). 


\subsection{Interactions between wildfire and other disturbance events}

Wildfire risk conditions often interact with other disturbance regimes, such as drought, biological invasions, and insect or disease outbreaks. In many cases, changing wildfire conditions both influence and are influenced by other forms of disturbance. For example, while drought increases the likelihood of wildfire as well as the susceptibility of trees to insect and disease outbreaks, these outbreaks also create favorable conditions for wildfire (Metz, Frangioso, Meentemeyer, \& Rizzo, 2011). Interactions among ecological processes feature complex dynamics, even before accounting for how climate change may alter these processes individually and collectively. As a result, uncertainty about wildfire risk conditions is greater when these conditions are more interdependent with other forms of disturbance (Millar, Stephenson, \& Stephens, 2007). In these settings, it may be more difficult for individuals to assess the efficacy of risk mitigation behavior because they may have less understanding of their exposure to risk as well as the prospective outcomes of mitigation behaviors (Neale \& Weir, 2015).

\section{I PSYCHOLOGICAL AND SOCIAL MEDIATING PROCESSES OF BEHAVIORAL ADAPTATION}

A growing body of research suggests that individuals do not modify risk mitigation behavior in direct response to changing hazard conditions. Rather, psychological and social processes have been shown to mediate the link between behavior and changing environmental conditions (Brenkert-Smith, Champ, \& Flores, 2012; Fischer \& Charnley, 2012; Grothmann \& Patt, 2005; McFarlane, McGee, \& Faulkner, 2011; McLennan, Paton, \& Beatson, 2015). We highlight here a range of psychological and social factors that have appeared consistently in research on wildfire risk mitigation behavior in settings characterized by changing hazard conditions.

\section{1 | Perceived risk}

Individuals generally have difficulty accurately appraising risk (Slovic, 1987; Slovic, Fischhoff, \& Lichtenstein, 1982), and may especially prone to misjudge risk from hazards that bear out over large spatial and temporal scales (Kondolf \& Podolak, 2014), which is a defining feature of wildfire hazards in many forested systems (Fischer, Spies, et al., 2016). Research has documented distinctions in how experts (e.g., fire management professionals) and non-experts (e.g., residents) assess wildfire risk (Zaksek \& Árvai, 2004). However, there is evidence that individuals in more hazardous landscapes are more concerned about wildfire, indicating that local biophysical conditions that determine "objective" risk levels can shape risk perception (Fischer et al., 2014). Whether informed by environmental cues, social interaction (Dickinson, Brenkert-Smith, Champ, \& Flores, 2015), or other drivers, level of perceived risk has repeatedly been shown to increase the likelihood that individuals undertake risk mitigation (Brenkert-Smith et al., 2012; W. E. Martin et al., 2009; McFarlane et al., 2011).

\section{2 | Perceived response efficacy}

Another reliable predictor of behavioral response to wildfire risk is an individual's expectation that the behavior is effective in reducing wildfire hazards or the scope of damages resulting from a wildfire. McFarlane et al. (2011) showed that homeowners in fire-prone communities in Alberta, Canada, were more likely to undertake risk mitigation activities if they assessed threats from wildfire to be sufficiently high, but also found that threat assessment was subject to perceived net benefits of risk mitigation such that residents discounted risk if they perceived the overall effectiveness of activities to be low. Perceived response efficacy has similarly been shown to increase the likelihood that individuals reduce vegetative fuels near homes (Dickinson et al., 2015) as well as create defensible space around homes through other practices (Brenkert-Smith, Champ, \& Flores, 2006; I. M. Martin, Bender, \& Raish, 2007).

\section{3 | Perceived self-efficacy}

Ample research demonstrates that individuals are more likely to take action to reduce wildfire risk when they perceive themselves capable of doing so. Although perceived self-efficacy is related to the concept of adaptive capacity in vulnerability research, which encompasses knowledge and other assets that may facilitate adaptation, a key distinction is that perceived self-efficacy depends not only on an objective measure of ability to undertake action, but individuals' confidence in their ability. Individuals who perceive themselves to be capable of implementing risk mitigation measures are more likely to do so (I. M. Martin et al., 2007; W. E. Martin et al., 2009). Self-efficacy may encompass multiple measures of capacity, each of which alone may be necessary but insufficient for undertaking behavioral change. For example, McFarlane et al. (2011) found 
that homeowners in Alberta, Canada, who believed they had the skills necessary for implementing risk mitigation activities were nevertheless reluctant to do so if they also believed they lacked sufficient financial resources.

\section{4 | Personal responsibility}

Because wildfires can spread across property boundaries, and often overwhelm the capacity of individual property owners, public agencies contribute to prevention and incident response efforts. Often certain wildfire risk mitigation responsibilities are formally designated. For example, some U.S. state forestry departments are obligated to attempt to suppress wildfires on privately owned lands (Bradshaw, 2010). Individual property owners vary in the degree to which they rely on others for risk mitigation, and research indicates that their attitude about personal responsibility is a key factor in their behavioral response to wildfire risk. Prior observation of successful suppression efforts may lead residents to entrust their protection to firefighters (Cohn, Williams, \& Carroll, 2008) and generally underestimate wildfire risk based on a false sense of security (McFarlane et al., 2011). However, when individuals perceive themselves to be responsible, they regard wildfire threats as more significant (McFarlane et al., 2011) and are more likely to undertake risk mitigation measures (W. E. Martin et al., 2009; McGee \& Russell, 2003).

\section{5 | Negative affect}

Wildfires can be dramatic events and can prompt strong affective responses. Individuals have been shown to prioritize information linked to emotion when making decisions (Finucane, Alhakami, Slovic, \& Johnson, 2000; Slovic, Finucane, Peters, \& MacGregor, 2007), a tendency known as the affect heuristic. In forested landscapes, the affect heuristic can influence risk perception and mitigation behavior among individuals who have experienced a wildfire, a close call, or media coverage of tragic wildfires. Residents who had been forced to evacuate from wildfires perceived the probability and negative consequences of wildfire to be greater (P. A. Champ \& Brenkert-Smith, 2016). Similarly, concern about wildfire was shown to be greater among forest owners who had experienced a wildfire (Fischer, 2011). Árvai, Gregory, Ohlson, Blackwell, and Gray (2006) found that the relationship between affective response and behavior depended upon whether individuals were indirectly or directly exposed to wildfire. Their study indicated that indirect exposure (e.g., living near a community that experienced a wildfire) could prompt a "postexposure wake-up call" and motivate behavioral responses intended to reduce future risk, while direct exposure dampened risk perception and intention to conduct mitigation behavior, due to "postexposure letdown."

\section{6 | Social interaction}

Peer effects also influence wildfire risk mitigation behavior. Individuals preferentially interact with other individuals with similar beliefs, values or experiences (McPherson, Smith-Lovin, \& Cook, 2001). This process of social selection may amplify the effects of social influence, the tendency for individuals to adopt characteristics of individuals with whom they interact, including behavior (Fowler \& Christakis, 2010). These mechanisms may explain the relationship between adoption of wildfire risk mitigation practices and patterns of informal interaction with friends, neighbors, and family members (Dickinson et al., 2015; Fischer \& Charnley, 2012; McCaffrey, 2004). For example, homeowners may be reluctant to mitigate risk through fuels reduction if such activities are at odds with community norms about landscaping (Monroe \& Nelson, 2004). Alternatively, social norms may incentivize risk mitigation behavior, for example, carrying out small-scale projects with neighbors to reduce shared risk (Brenkert-Smith, 2010). Research has also shown that individuals who interact with others about fire are more likely to reduce vegetative fuels (Dickinson et al., 2015; Fischer et al., 2014).

\section{I BEHAVIORAL RESPONSES TO WILDFIRE RISK}

The preceding sections have referenced several examples of the wide range of wildfire risk mitigation behaviors, which can be categorized several different ways. One approach distinguishes between the types of specific actions undertaken (e.g., installation of fire-proof roofing). An alternative approach focuses on individuals' more general behavioral strategies (e.g., how proactively individuals respond to hazard conditions).

\section{1 | Behavioral adaptation actions}

Risk mitigation measures undertaken by individuals in wildfire-prone regions typically involve either the modification of structures such as homes or the reduction of flammable vegetation, both near homes and other valuable structures as well as throughout forested areas of private properties. 
Structural mitigation actions include installation of fire-proof roofs and siding, adding screening over roof vents, cleaning roofs of fallen branches, and improving accessibility from main roads (Brenkert-Smith, Meldrum, \& Champ, 2015; P. A. Champ, Donovan, \& Barth, 2013; Collins, 2008; I. M. Martin et al., 2007; W. E. Martin et al., 2009; McFarlane et al., 2011). These actions primarily function to reduce the likelihood that a house or other structure catches fire from embers or radiant heat.

Individuals also seek to limit wildfire risk by reducing flammable vegetation near homes. Specific actions include cutting trees or pruning branches within several meters of structures, using "fire-safe" plants in landscaping, raking up and removing dry leaf litter such as pine needles from yards, and regularly mowing long grasses around structures (Brenkert-Smith et al., 2015; P. A. Champ et al., 2013; Collins, 2008; Dickinson et al., 2015; W. E. Martin et al., 2009). These actions serve to decrease the likelihood that fire burns at high intensity in close proximity to structures.

Personal safety and structures are not the only values at stake in wildfire-prone areas. Individuals who manage forests for timber or who wish to protect aesthetic, cultural, or other qualities of forested land undertake forest management practices in response to wildfire risk. For example, individuals reduce hazardous fuels at the stand- or property-level through precommercial thinning, mastication of small-diameter woody material, pile burning, and understory burning (Calkin, Cohen, Finney, \& Thompson, 2014; Rummer, 2008), sometimes in cooperation with neighbors (Fischer \& Charnley, 2012). Forest owners may also alter tree harvest schedules or replant woodlots with fire-adapted trees (Fischer, 2011; Peter \& Nelson, 2005).

\section{2 | Behavioral adaptation strategies}

Although much research on individual-level responses to wildfire risk focuses on behavioral actions, this level of specificity presents a challenge for understanding behavioral adaptation because a large number of actions may define an individual's behavioral response to changing wildfire hazard conditions. Additionally, the manner in which these actions are carried out may vary widely within a population of individuals. For example, the prospective efficacy of fuels reduction depends upon a range of factors unique to each individual and local environmental setting. An alternative approach is to focus on more general behavioral strategies, which reveal how individuals negotiate trade-offs that typically relate to the prospective efficacy and cost of different approaches for mitigating risk. New environmental conditions can alter the appropriateness of an individual's approach for responding to risk, prompting the individual to adjust her strategy or risk adverse impacts. These adjustments constitute behavioral adaptation when they result in beneficial outcomes for the individuals undertaking them. Below, we describe four dimensions that can help to characterize the strategies by which individuals respond to changing wildfire hazard conditions. While these tendencies by no means encompass all aspects of behavior, they nevertheless provide a foundation for study of behavioral adaptation to climate change in wildfire-prone forests.

\subsection{1 | Proactive-Reactive}

Some people prepare extensively for potential exposure to wildfire, while others wait to experience a fire event before responding (Brenkert-Smith et al., 2006). The timing at which individuals undertake risk mitigation involves a trade-off between level of investment and potential efficacy, subject to uncertainty. Proactive strategies, which emphasize preventative measures such as fuels reduction over fire exclusion and suppression (J. G. Champ, Brooks, \& Williams, 2012), may entail greater upfront investment in time and resources, and their overall effectiveness may hinge on long-term commitments to collaborative planning (Cheng \& Mattor, 2010). Individuals who behave less proactively have more opportunities to iteratively reappraise the risks they face as well as the likely outcomes of various tactics for addressing those risks before committing to a mitigation action. On the other hand, reactive strategies such as suppression allow build-up of fuels over time, effectively transferring the expense of costlier fire suppression efforts to the future (Borchers, 2005).

\subsection{2 | Innovative-Conventional}

Changing wildfire risk conditions highlight the prospective value of new approaches for protection of structural assets and for forest management, despite uncertainty of their efficacy and their greater up-front costs relative to more conventional approaches. Drawing upon diffusion of innovation theory (Rogers, 2003), McCaffrey and Kumagai (2007) describe novel wildfire risk mitigation practices as preventive innovations, which may be less appealing than conventional practices due to the low probability that a prospective adopter actually experiences a fire. Additionally, individuals in some fire-prone regions may be particularly reluctant to adjust wildfire risk mitigation practices that are based on ecological knowledge accumulated over long periods of time, including multiple generations (Paveglio, Carroll, Hall, \& Brenkert-Smith, 2015). Even if individuals perceive new risk mitigation practices to be more effective, innovation typically features greater up-front costs compared with maintaining familiar practices. For example, landowners may be aware that prescribed burning is an increasingly appropriate land management practice for reducing risk of losses from catastrophic wildfire (Calkin et al., 2014; Martinson \& Omi, 2013). However, to begin conducting prescribed burns, landowners might need to acquire technical skills, learn to navigate 
regulatory processes, and overcome other obstacles (Spencer, Schultz, \& Hoffman, 2015). The degree to which individuals approach wildfire risk mitigation through a more innovative or conventional behavioral strategy depends on how they navigate a trade-off defined by the challenges (e.g., expense, learning curve) of undertaking activities that may be more effective under changing wildfire risk conditions.

\subsection{3 | Diversity-Specialization}

Individuals may respond to changing wildfire hazard conditions by investing heavily in a limited set of practices or may seek to hedge their bets on a more diverse set of behaviors. A behavioral strategy that emphasizes diversity will likely include at least one successful risk mitigation practice. The degree to which a behavioral strategy should emphasize diversity depends in part on the level of uncertainty under which decisions are made. In the context of wildfire risk mitigation through forest management, because individuals are constrained by limited information about how decisions may play out over long time horizons, it may be unclear which specific behaviors will yield desirable outcomes (Hildebrandt \& Knoke, 2011). Uncertainty may relate to high variability of environmental conditions (Peterson et al., 1997), such as the likelihood that a particular individual will experience a wildfire in a given year. Uncertainty may also stem from limited understanding of the relationships among causal factors, or even the existence of key factors (Peterson et al., 1997), which limits an individual's capacity to assess the probability of experiencing a wildfire. Under these conditions, an individual whose behavioral strategy emphasizes specialization rather than diversity may experience poor outcomes if the limited set of practices implemented excludes the most effective practices, due to high uncertainty. When uncertainty is low, the optimal level of behavioral diversity likewise decreases, because individuals may specialize in only those behaviors known to be effective, thereby avoiding unnecessary expenses associated with ineffective behaviors. For this reason, an ideal degree of diversification of risk mitigation measures depends on an individual's level of confidence in the efficacy of each measure as well as the individual's overall risk tolerance.

\subsection{4 | Collective-Individual}

In wildfire-prone forests, individuals vary in the degree to which they implement risk mitigation practices in coordination with neighbors or other landowners nearby (Brenkert-Smith et al., 2006). Increasingly intense and uncontrollable wildfires highlight the utility of multiproperty risk-mitigation efforts, which might feature coordinated action to reduce fuel loads across neighboring land parcels (Busby et al., 2012). Similarly, the scale of wildfire risk conditions may require collective action at the landscape level to reconcile diverse land use preferences among heterogeneous groups of land managers (Fischer, VanceBorland, Jasny, Grimm, \& Charnley, 2016). Some actions are inherently more collective than others (e.g., working with neighbors construct a fuel break versus reducing flammable vegetation surrounding a property). However, most actions can be implemented in different ways depending on how collectively an individual approaches wildfire risk mitigation. For example, an individual with a more individualistic behavioral strategy may contribute less to a community-level fuel clean-up program. Through collective action, individuals may benefit from greater access to information about the causes, implications, and viable responses to complex or rapidly changing environmental conditions. However, behaving more collectively exposes individuals to other costs associated with collaboration, and individuals may additionally lack assurance that their contributions to collective risk mitigation efforts will be matched by others (Canadas, Novais, \& Marques, 2016). Individuals must thus optimize the degree to which they invest in collective actions, which may be more effective in reducing wildfire risk, but also feature higher costs.

\section{7 | OUTCOMES}

The IPCC emphasizes that adaptation "moderates harm or exploits beneficial opportunities" (Mach et al., 2014, p. 117). The most adaptive behavioral responses are those that most effectively avoid or minimize adverse effects of wildfire because they are most suitable to changing wildfire hazard conditions. Assessment of the efficacy of behaviors can be complicated because the goals of risk mitigation may vary considerably from one individual to the next. For example, one homeowner may be primarily motivated to reduce wildfire risk out of concern for home protection, while another may care most about timber assets. Research on social diversity within wildfire-prone landscapes highlights a variety of values threatened by changing hazard conditions (K. C. Nelson et al., 2005; Paveglio, Carroll, Stasiewicz, Williams, \& Becker, in press). One way to distinguish between these various goals of risk mitigation behavior is to evaluate outcomes in terms of effects on capital assets, which may relate to human, financial, natural, or cultural capital. 


\section{1 | Human capital}

Although human capital encompasses a range of assets, including skills and knowledge, in the context of wildfire hazards, key indicators relate to health and safety. Correspondingly, many risk mitigation behaviors primarily serve to address health and safety concerns. For example, residents may improve road access to help themselves evacuate safely on short notice. Likewise, a resident's degree of concern for personal safety shapes decisions about when (or whether) to evacuate (McCaffrey, Wilson, \& Konar, 2017). The tragic outcomes of the 2009 "Black Saturday" fires in Victoria, Australia, in which 173 people lost their lives, many while defending their homes, prompted a reevaluation of the appropriateness of the "Stay and Defend or Leave Early" strategy (Paveglio et al., 2010). By contrast, a study of five communities in Victoria, Australia, that experienced high-intensity wildfires in 2003, resulting in destruction of 43 homes but no fatalities, revealed extensive support for "Stay and Defend or Leave Early" (Tibbits \& Whittaker, 2007).

\section{2 | Financial capital}

Individuals undertake a range of wildfire risk mitigation measures to protect homes and other financial assets. For these behaviors to be effective, they must be undertaken at scales commensurate with hazard conditions. For example, a study of homeowners living in a community in Colorado, USA, in which 169 homes would later be destroyed by a wildfire, found that nearly all respondents (96\%) had implemented some form of structural or vegetative risk mitigation action designed to protect homes (Brenkert-Smith \& Champ, 2011). The magnitude of property loss despite near universal adoption of mitigation measures indicated that homeowners' levels of investment protective action may have proved insufficient in light of the scale of hazard conditions they faced.

\section{3 | Natural capital}

For private forest owners, wildfire can threaten timber and other forms of natural capital. Fuel breaks, especially along property boundaries, serve to reduce the likelihood of wildfire spreading to valuable timber stands, while fuel reduction practices (e.g., precommercial thinning, understory burning) can decrease tree mortality should a wildfire enter a woodlot (Konoshima, Albers, Montgomery, \& Arthur, 2010; Konoshima, Montgomery, Albers, \& Arthur, 2008). Fischer et al. (2014) found that forest owners who had previously experienced wildfire within on their parcels were more concerned about wildfire risk, and were more likely to conduct fuels reduction if they managed land for timber production and were concerned about wildfire risk, indicating a potential linkage between prior losses and behavior intended to reduce risk to natural capital assets.

\section{4 | Cultural capital}

Many people living in wildfire-prone forests have strong place-based attachment to their surroundings. Research indicates that people knowingly move to areas at risk of fire because they place high value in the aesthetic qualities of these landscapes or for the lifestyle that is possible in these places (Brenkert-Smith et al., 2013). Throughout much of the western United States, retirees, amenity seekers, and second-home buyers have migrated to communities formerly dependent on natural resources (Abrams, Gosnell, Gill, \& Klepeis, 2012). This demographic change has led to a shift in the types of values at risk from wildfire and public preferences for wildfire risk mitigation. Studies conducted in wildfire-prone communities and regions that had recently experienced wildfires have found that risk mitigation behaviors were shaped by motivation to protect scenic qualities of the landscape, recreational opportunities, a sense of privacy, and other place-based values (Gordon, Gruver, Flint, \& Luloff, 2013; McCaffrey et al., 2011).

The range of values at risk from wildfire adds complexity to the task of evaluating behavioral adaptation because a risk mitigation action or strategy that most effectively moderates adverse impacts to one value may function less effectively to protect other values. Recent research has documented extensive diversity at the community level in the values residents regard to be at risk from wildfire (Carroll \& Paveglio, 2016). Likewise, within communities undergoing demographic transitions, values at risk may differ significantly from one neighbor to the next. Consequently, the degree to which a behavior is adaptive is highly context-dependent. Adaptiveness depends not only on the degree to which a behavior "fits" changing hazard conditions, but also the values of individuals. 


\section{I REFLECTIONS ON CURRENT UNDERSTANDING OF BEHAVIORAL ADAPTATION TO CLIMATE CHANGE IN WILDFIRE-PRONE FORESTS}

We have summarized findings from diverse fields of research on the relationships that span climate change, wildfire hazard conditions, psychological and social drivers of risk mitigation behavior, and the outcomes of behavior. Building upon the simplified depiction of the core components of behavioral adaptation to climate change (Figure 1), we synthesize these relationships in a dynamic and coupled framework for analysis of behavioral adaptation to climate change in wildfire-prone forests (Figure 2). As depicted in the framework, hazard conditions are jointly shaped by climate change and forest management behaviors. Hazard conditions in turn affect the likelihood of wildfire and associated impacts on an individual's assets. A range of affective, cognitive, and social processes mediate the relationship between observation/experience of wildfire and behavioral response to wildfire risk. Specific risk mitigation actions (which may in turn affect hazard conditions) depend on an individual's overall strategy for risk mitigation.

A key feature of this framework is the two-way linkage between behavior and outcomes via hazard conditions and psychosocial mediating processes. This form of feedback is absent in dominant frameworks on risk mitigation such as the MPPACC (Grothmann \& Patt, 2005). Although one could argue that iterative evaluation of the appropriateness of behavioral response should feature prominently in any model of behavioral adaptation, accounting for feedbacks is crucial in wildfire-prone systems where hazard conditions are so strongly shaped by individual-level responses to risk (e.g., fire exclusion can hasten the accumulation of fuels, while understory burning can reduce flammable vegetation). Although research has documented disconnects between individuals' levels of preparedness and the scope of surrounding hazard conditions (Brenkert-Smith \& Champ, 2011; Paveglio, Edgeley, \& Stasiewicz, 2018), most studies that have included biophysical variables as explanatory factors of risk mitigation behavior have found a positive relationship between "objective" risk and response (Fischer et al., 2014; Olsen et al., 2017). Similarly, although few studies measure how individuals update behavior in terms of incurred or averted losses, numerous studies have documented a significant relationship between wildfire experience and response, indicating that individuals may reflect on outcomes of prior behavior when evaluating prospective future behavior.

While much is known about relationships among subsets of factors depicted in the framework, very few studies "close the loop" by evaluating behavioral change as an iterative process. The dominant approach in research on individual-level response to wildfire risk focuses on factors that shape behavior at one time. An exception is a laboratory experiment by Little, Prante,

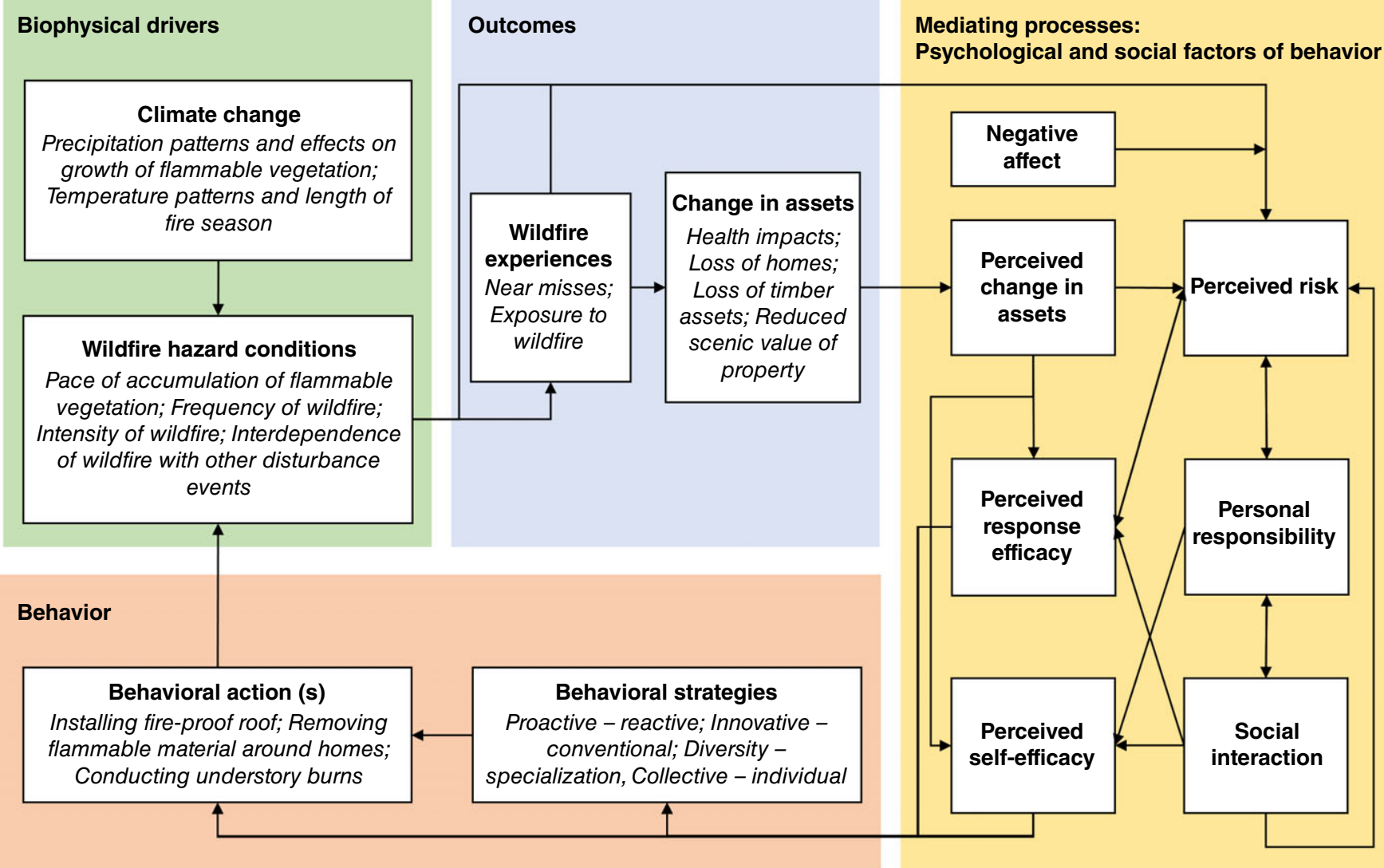

FIGURE 2 A framework of behavioral adaptation to climate change in wildfire-prone forests 
Jones, McKee, and Berrens (2017) that examined how individuals update decisions about investments in fuels reduction and insurance based on losses from "fires" at earlier rounds in the experiment as well as access to information about risk mitigation expenditures on "neighboring parcels." This approach is valuable not only for understanding the dynamics of behavioral adaptation, but also for evaluating the degree to which behaviors are truly adaptive in the sense that they provide better outcomes. For example, in the study conducted by Little et al., participants' motivation to maximize their financial assets over the course of the experiment, which corresponded to real earnings following the experiment, functioned to select for behaviors that best fit hazard conditions, subject to contextual treatments such as information availability. Improving theoretical understanding of behavioral adaptation and developing policy tools to encourage more adaptive behaviors will require more research, especially in nonlaboratory settings, that accounts for behavioral change over time.

Our review also reveals very little attention to variation in wildfire risk mitigation behaviors. Commonly, studies examine whether individuals undertake one or more behaviors, rather than how these behaviors are carried out. This approach is problematic because individuals may implement a given behavior in different ways. For example, the practice of fuels reduction encompasses numerous activities (e.g., thinning, pile burning, mastication of woody material), and each activity can additionally be implemented in different ways. As a result, a generic risk mitigation behavior may be highly adaptive in one context but not in others.

Similarly, there is limited research on how variation in wildfire hazard conditions shape behavior. Among studies that did include biophysical variables in models of behavior, most collapsed these variables into a single measure of wildfire hazard (P. A. Champ et al., 2013; Fischer et al., 2014). One exception was a recent study by Olsen et al. (2017) that included separate variables related to the likelihood of wildfire (burn probability) and potential wildfire intensity (conditional flame length). Evaluation of variation in behavior as a function of variation in wildfire hazards is crucial for evaluation of the adaptiveness of behaviors (e.g., a behavior may be appropriate in locations that experience frequent but low-intensity wildfires, while less appropriate if wildfires are infrequent but high-intensity) and remains an important research gap.

\section{9 | CONCLUSION: AN AGENDA FOR FUTURE RESEARCH}

Addressing gaps in our current understanding of behavioral adaptation to climate change in wildfire-prone forests will require more research on how individuals adjust their behavior over time, as well as more rigorous measurement of variation in behavior and hazard conditions.

Longitudinal research, experiments, and computational modeling may be particularly appropriate for advancing understanding of how behaviors change over time in response to changing hazard conditions, subject to psychological and social processes. In particular, methods for evaluating outcomes of behavior will need to account for changes in capital assets over time. For example, researchers may hypothesize that more collective behavioral strategies may become more prevalent among forest owners managing for timber production under conditions of increased wildfire intensity, because these conditions increase the net benefits (avoided losses minus implementation costs) of cooperative wildfire risk mitigation over larger spatial scales relative to more individualist actions. Testing this expectation might require annual information about wildfire impacts, the relative investment in risk mitigation activities implemented in collaboration with others versus alone, and timber production. Within the same study system, separate hypotheses may explore how the relationship between avoided losses and collective behavior may be conditional on the familiarity with neighbors (i.e., a measure of social interaction), or how faith that neighbors will follow through on agreements to undertake risk mitigation shapes expectations of the value of joint action (i.e., a measure of perceived response efficacy). Accounting for how feedbacks shape behavioral change over time may add challenges to empirical data collection, but can yield important insights about the dynamics of behavioral adaptation as well as its implications. For example, under certain conditions of environmental change, behavioral strategies may stabilize (e.g., individuals maintain a certain proportion of conservative versus experimental actions, though the actions themselves may change). Alternatively, environmental change may produce dynamic equilibria in which the balance between behavioral strategies oscillates (e.g., behavior is mostly collective one year when the spatial scale of hazardous fuel conditions increases the value of cooperation across ownership boundaries, then individualistic the next year), or no equilibrium at all.

In the future, research would benefit from greater attention to variation in behaviors, which may require knowledge about how a given action is implemented differently within a population prior to data collection. An alternative approach would involve focusing on behavioral strategies (e.g., more or less proactive), which may be conceptualized as continuous variables. Compared to specific behavioral actions, the general nature of strategies may better facilitate development of theories of behavioral adaptation. Because strategies inherently reflect trade-offs involving cost-effectiveness and uncertainty, they are related to cognitive appraisal of changing hazard conditions. Similarly, variation in hazard conditions merits greater attention in research on risk mitigation behavior. Specifically, future research should move beyond using a generic measure of hazard based on one or more biophysical variables (or highlighting hazard conditions as a backdrop when describing the study 
system), and test hypotheses about how characteristics of environmental change (e.g., reduction in fire return intervals, or increases in the intensity of wildfire) affect behavior. This approach will help advance understanding of which behaviors are truly adaptive under different conditions of environmental change. Of particular relevance to policy-makers are situations in which changing hazard conditions preclude behavioral adaptation. These cases may feature lags in feedback loops involving behavior, changing hazard conditions, and changes in capital assets, which distort an individual's ability to understand the prospective outcomes of behavior. In other situations, in which cognitive biases drive behavioral responses to environmental change to local optima, policy interventions could help individuals adopt more adaptive behaviors at different points in the feedback cycle (e.g., providing actionable information about environmental change to incentivize proactive behavior, or offsetting the costs of attending community meetings to incentivize collective behavior). A better understanding of the process of behavioral adaptation can assist policy-makers in identifying conditions under which behaviors are adaptive from the perspective of the individuals implementing them, but are nevertheless maladaptive in terms of outcomes at the community or regional level. For example, if individuals who purchase comprehensive home insurance are less inclined to maintain defensible space around their homes, they may put neighboring homes at risk from structure-to-structure ignition.

More generally, advancing understanding of behavioral adaptation to climate change in wildfire-prone systems will require more meaningful collaboration research spanning the social and natural sciences (e.g., Fischer et al., 2014; Olsen et al., 2017). For example, developing greater theoretical understanding of how individuals update behaviors in light of changing hazard conditions will require more extensive engagement by social scientists with natural and physical scientists, including ecologists and climate scientists. Likewise, efforts to model change in forest ecosystems over timescales commensurate with climate change-largely the domain of natural scientists—will benefit from collaboration with social scientists, given the scope of human influence over hazard conditions in fire-prone landscapes.

\section{ACKNOWLEDGMENTS}

Funding for this study was provided by the MCubed, University of Michigan funding program.

\section{CONFLICT OF INTEREST}

The authors have declared no conflicts of interest for this article.

\section{RELATED WIRES ARTICLES}

Predicting climate change effects on wildfires requires linking processes across scales

The climate-wildfire-air quality system: interactions and feedbacks across spatial and temporal scales

Climate-vegetation-fire interactions and feedbacks: trivial detail or major barrier to projecting the future of the Earth system?

\section{REFERENCES}

Abatzoglou, J. T., \& Kolden, C. A. (2013). Relationships between climate and macroscale area burned in the western United States. International Journal of Wildland Fire, 22(7), 1003-1020.

Abrams, J. B., Gosnell, H., Gill, N. J., \& Klepeis, P. J. (2012). Re-creating the rural, reconstructing nature: An international literature review of the environmental implications of amenity migration. Conservation and Society, 10(3), 270-284. https://doi.org/10.4103/0972-4923.101837

Adger, W. N., Kelly, P. M., \& Ninh, N. H. (2012). Living with environmental change: Social vulnerability, adaptation and resilience in Vietnam. London: Routledge.

Ager, A. A., Day, A., Finney, M. A., Vance-Borland, K., \& Vaillant, N. M. (2014). Analyzing the transmission of wildfire exposure on a fire-prone landscape in Oregon, USA. Forest Ecology and Management, 334, 377-390. https://doi.org/10.1016/j.foreco.2014.09.017

Árvai, J., Gregory, R., Ohlson, D., Blackwell, B., \& Gray, R. (2006). Letdowns, wake-up calls, and constructed preferences: People's responses to fuel and wildfire risks. Journal of Forestry, 104(4), 173-181.

Berrang-Ford, L., Ford, J. D., \& Paterson, J. (2011). Are we adapting to climate change? Global Environmental Change, 21(1), 25-33. https://doi.org/10.1016/j.gloenvcha.2010. 09.012

Birkmann, J. (2011). First- and second-order adaptation to natural hazards and extreme events in the context of climate change. Natural Hazards, 58(2), 811-840. https://doi.org/10.1007/s11069-011-9806-8

Blaikie, P., Cannon, T., Davis, I., \& Wisner, B. (2014). At risk: Natural hazards, people's vulnerability and disasters. London: Routledge.

Borchers, J. G. (2005). Accepting uncertainty, assessing risk: Decision quality in managing wildfire, forest resource values, and new technology. Forest Ecology and Management, 211(1), 36-46. https://doi.org/10.1016/j.foreco.2005.01.025

Bowman, D. M. J. S., Balch, J., Artaxo, P., Bond, W. J., Cochrane, M. A., D'Antonio, C. M., ... Swetnam, T. W. (2011). The human dimension of fire regimes on earth. Journal of Biogeography, 38(12), 2223-2236. https://doi.org/10.1111/j.1365-2699.2011.02595.x

Bradshaw, K. M. (2010). A modern overview of wildfire law. Fordham Environmental Law Review, 21, $445-478$.

Brenkert-Smith, H. (2010). Building bridges to fight fire: The role of informal social interactions in six Colorado wildland? Urban interface communities. International Journal of Wildland Fire, 19(6), 689. https://doi.org/10.1071/WF09063

Brenkert-Smith, H., \& Champ, P. A. (2011). Fourmile canyon: Living with wildfire. Fire Management Today, $71(2), 33$. 
Brenkert-Smith, H., Champ, P. A., \& Flores, N. (2006). Insights into wildfire mitigation decisions among wildland-urban Interface residents. Society \& Natural Resources, 19(8), 759-768. https://doi.org/10.1080/08941920600801207

Brenkert-Smith, H., Champ, P. A., \& Flores, N. (2012). Trying not to get burned: Understanding Homeowners' wildfire risk-mitigation behaviors. Environmental Management, 50(6), 1139-1151. https://doi.org/10.1007/s00267-012-9949-8

Brenkert-Smith, H., Dickinson, K. L., Champ, P. A., \& Flores, N. (2013). Social amplification of wildfire risk: The role of social interactions and information sources. Risk Analysis, 33(5), 800-817. https://doi.org/10.1111/j.1539-6924.2012.01917.x

Brenkert-Smith, H., Meldrum, J. R., \& Champ, P. A. (2015). Climate change beliefs and hazard mitigation behaviors: Homeowners and wildfire risk. Environmental Hazards, 14(4), 341-360. https://doi.org/10.1080/17477891.2015.1080656

Burton, I. (1993). The environment as hazard. New York, NY: Guilford Press.

Busby, G. M., Albers, H. J., \& Montgomery, C. A. (2012). Wildfire risk management in a landscape with fragmented ownership and spatial interactions. Land Economics, 88(3), 496-517. https://doi.org/10.3368/le.88.3.496

Calkin, D. E., Cohen, J. D., Finney, M. A., \& Thompson, M. P. (2014). How risk management can prevent future wildfire disasters in the wildland-urban interface. Proceedings of the National Academy of Sciences, 111(2), 746-751. https://doi.org/10.1073/pnas.1315088111

Calkin, D. E., Thompson, M. P., \& Finney, M. A. (2015). Negative consequences of positive feedbacks in US wildfire management. Forest Ecosystems, 2(1), 1-10. https://doi.org/10.1186/s40663-015-0033-8

Canadas, M. J., Novais, A., \& Marques, M. (2016). Wildfires, forest management and landowners' collective action: A comparative approach at the local level. Land Use Policy, 56, 179-188. https://doi.org/10.1016/j.landusepol.2016.04.035

Carroll, M., \& Paveglio, T. (2016). Using community archetypes to better understand differential community adaptation to wildfire risk. Philosophical Transactions of the Royal Society B: Biological Sciences, 371(1696), 20150344. https://doi.org/10.1098/rstb.2015.0344

Chambers, R. (1989). Vulnerability: How the poor cope. IDS Bulletin, 20(2), 33-40.

Champ, J. G., Brooks, J. J., \& Williams, D. R. (2012). Stakeholder understandings of wildfire mitigation: A case of shared and contested meanings. Environmental Management, 50(4), 581-597. https://doi.org/10.1007/s00267-012-9914-6

Champ, P. A., \& Brenkert-Smith, H. (2016). Is seeing believing? Perceptions of wildfire risk over time. Risk Analysis, 36(4), 816-830. https://doi.org/10.1111/risa.12465

Champ, P. A., Donovan, G. H., \& Barth, C. M. (2013). Living in a tinderbox: Wildfire risk perceptions and mitigating behaviours. International Journal of Wildland Fire, 22(6), 832-840.

Chapin, F. S., Trainor, S. F., Huntington, O., Lovecraft, A. L., Zavaleta, E., Natcher, D. C., ... Naylor, R. L. (2008). Increasing wildfire in Alaska's Boreal Forest: Pathways to potential solutions of a wicked problem. BioScience, 58(6), 531-540. https://doi.org/10.1641/B580609

Cheng, A. S., \& Mattor, K. M. (2010). Place-based planning as a platform for social learning: Insights from a National Forest Landscape Assessment Process in western Colorado. Society \& Natural Resources, 23(5), 385-400. https://doi.org/10.1080/08941920802178198

Clayton, S., Devine-Wright, P., Stern, P. C., Whitmarsh, L., Carrico, A., Steg, L., ... Bonnes, M. (2015). Psychological research and global climate change. Nature Climate Change, 5(7), 640-646. https://doi.org/10.1038/nclimate2622

Cohn, P. J., Williams, D. R., \& Carroll, M. S. (2008). Wildland-urban residents' views on risk and attribution. In W. E. Martin, C. Raish, \& B. M. Kent (Eds.), Wildfire risk: Human perceptions and management implications (pp. 23-43). Washington, DC: Resources for the Future.

Collins, T. W. (2005). Households, forests, and fire hazard vulnerability in the American West: A case study of a California community. Environmental Hazards, 6(1), 23-37. https://doi.org/10.1016/j.hazards.2004.12.003

Collins, T. W. (2008). What influences hazard mitigation? Household decision making about wildfire risks in Arizona's White Mountains. The Professional Geographer, 60(4), 508-526. https://doi.org/10.1080/00330120802211737

Denevan, W. M. (1983). Adaptation, variation, and cultural geography. The Professional Geographer, 35(4), 399-407. https://doi.org/10.1111/j.0033-0124.1983. 00399.x

Dickinson, K., Brenkert-Smith, H., Champ, P., \& Flores, N. (2015). Catching fire? Social interactions, beliefs, and wildfire risk mitigation behaviors. Society \& Natural Resources, 28(8), 807-824. https://doi.org/10.1080/08941920.2015.1037034

Dobzhansky, T. (1968). On some fundamental concepts of Darwinian biology. In T. Dobzhansky, M. K. Hecht, \& W. C. Steere (Eds.), Evolutionary biology (pp. 1-34). Boston, MA: Springer US. https://doi.org/10.1007/978-1-4684-8094-8_1

Dovers, S. R., \& Hezri, A. A. (2010). Institutions and policy processes: The means to the ends of adaptation. WIREs Climate Change, 1(2), 212-231. https://doi.org/10.1002/ wcc. 29

Dupuis, J., \& Biesbroek, R. (2013). Comparing apples and oranges: The dependent variable problem in comparing and evaluating climate change adaptation policies. Global Environmental Change, 23(6), 1476-1487. https://doi.org/10.1016/j.gloenvcha.2013.07.022

Fankhauser, S., Smith, J. B., \& Tol, R. S. J. (1999). Weathering climate change: Some simple rules to guide adaptation decisions. Ecological Economics, $30(1)$, 67-78. https://doi.org/10.1016/S0921-8009(98)00117-7

Fazey, I., Wise, R. M., Lyon, C., Câmpeanu, C., Moug, P., \& Davies, T. E. (2016). Past and future adaptation pathways. Climate and Development, 8(1), 26-44. https:// doi.org/10.1080/17565529.2014.989192

Finucane, M. L., Alhakami, A., Slovic, P., \& Johnson, S. M. (2000). The affect heuristic in judgments of risks and benefits. Journal of Behavioral Decision Making, $13(1), 1-17$.

Fischer, A. P. (2011). Reducing hazardous fuels on nonindustrial private forests: Factors influencing landowner decisions. Journal of Forestry, 109(5), $260-266$.

Fischer, A. P. (2018). Pathways of adaptation to external stressors in coastal natural-resource-dependent communities: Implications for climate change. World Development, 108, 235-248.

Fischer, A. P., \& Charnley, S. (2012). Risk and cooperation: Managing hazardous fuel in mixed ownership landscapes. Environmental Management, 49(6), $1192-1207$. https://doi.org/10.1007/s00267-012-9848-z

Fischer, A. P., Kline, J. D., Ager, A. A., Charnley, S., \& Olsen, K. A. (2014). Objective and perceived wildfire risk and its influence on private forest landowners' fuel reduction activities in Oregon's (USA) ponderosa pine ecoregion. International Journal of Wildland Fire, 23(1), 143-153.

Fischer, A. P., Spies, T. A., Steelman, T. A., Moseley, C., Johnson, B. R., Bailey, J. D., ... Bowman, D. M. (2016). Wildfire risk as a socioecological pathology. Frontiers in Ecology and the Environment, 14(5), 276-284. https://doi.org/10.1002/fee.1283

Fischer, A. P., Vance-Borland, K., Jasny, L., Grimm, K. E., \& Charnley, S. (2016). A network approach to assessing social capacity for landscape planning: The case of fire-prone forests in Oregon, USA. Landscape and Urban Planning, 147, 18-27. https://doi.org/10.1016/j.landurbplan.2015.10.006

Fowler, J. H., \& Christakis, N. A. (2010). Cooperative behavior cascades in human social networks. Proceedings of the National Academy of Sciences, 107(12), 5334-5338. https://doi.org/10.1073/pnas.0913149107

Gan, J., Jarrett, A., \& Gaither, C. J. (2015). Landowner response to wildfire risk: Adaptation, mitigation or doing nothing. Journal of Environmental Management, 159, 186-191. https://doi.org/10.1016/j.jenvman.2015.06.014

Gergel, D. R., Nijssen, B., Abatzoglou, J. T., Lettenmaier, D. P., \& Stumbaugh, M. R. (2017). Effects of climate change on snowpack and fire potential in the western USA. Climatic Change, 141(2), 287-299. https://doi.org/10.1007/s10584-017-1899-y 
Gordon, J. S., Gruver, J. B., Flint, C. G., \& Luloff, A. (2013). Perceptions of wildfire and landscape change in the Kenai Peninsula, Alaska. Environmental Management, 52(4), 807-820.

Grothmann, T., \& Patt, A. (2005). Adaptive capacity and human cognition: The process of individual adaptation to climate change. Global Environmental Change, 15(3), 199-213. https://doi.org/10.1016/j.gloenvcha.2005.01.002

Haasnoot, M., Kwakkel, J. H., Walker, W. E., \& ter Maat, J. (2013). Dynamic adaptive policy pathways: A method for crafting robust decisions for a deeply uncertain world. Global Environmental Change, 23(2), 485-498. https://doi.org/10.1016/j.gloenvcha.2012.12.006

Harris, R. M. B., Remenyi, T. A., Williamson, G. J., Bindoff, N. L., \& Bowman, D. M. J. S. (2016). Climate-vegetation-fire interactions and feedbacks: Trivial detail or major barrier to projecting the future of the Earth system? WIREs Climate Change, 7(6), 910-931. https://doi.org/10.1002/wcc.428

Head, L. (2009). Cultural ecology: Adaptation - Retrofitting a concept? Progress in Human Geography, 34, 234-242. https://doi.org/10.1177/0309132509338978

Hewitt, K. (1997). Regions of risk: A geographical Introduction to disasters. London: Longman.

Hildebrandt, P., \& Knoke, T. (2011). Investment decisions under uncertainty-A methodological review on forest science studies. Forest Policy and Economics, 13(1), 1-15. https://doi.org/10.1016/j.forpol.2010.09.001

Holling, C. S. (1973). Resilience and stability of ecological systems. Annual Review of Ecology and Systematics, 4, 1-23.

Kasperson, R. E., Renn, O., Slovic, P., Brown, H. S., Emel, J., Goble, R., ... Ratick, S. (1988). The social amplification of risk: A conceptual framework. Risk Analysis, 8(2), 177-187. https://doi.org/10.1111/j.1539-6924.1988.tb01168.x

Kates, R. W., Travis, W. R., \& Wilbanks, T. J. (2012). Transformational adaptation when incremental adaptations to climate change are insufficient. Proceedings of the National Academy of Sciences, 109(19), 7156-7161. https://doi.org/10.1073/pnas.1115521109

Kondolf, G. M., \& Podolak, K. (2014). Space and time scales in human-landscape systems. Environmental Management, 53(1), 76-87. https://doi.org/10.1007/ s00267-013-0078-9

Konoshima, M., Albers, H. J., Montgomery, C. A., \& Arthur, J. L. (2010). Optimal spatial patterns of fuel management and timber harvest with fire risk. Canadian Journal of Forest Research, 40(1), 95-108. https://doi.org/10.1139/X09-176

Konoshima, M., Montgomery, C. A., Albers, H. J., \& Arthur, J. L. (2008). Spatial-endogenous fire risk and efficient fuel management and timber harvest. Land Economics, 84(3), 449-468. https://doi.org/10.3368/le.84.3.449

Little, J. M., Prante, T., Jones, M. L., McKee, M., \& Berrens, R. P. (2017). Addressing the private wildfire risk mitigation paradox in a climate-altered wildland urban interface. In World scientific reference on natural resources and environmental policy in the era of global change: Volume 4: Experimental economics (pp. 71-94). Hackensack, NJ: World Scientific.

Mach, K. J., Planton, S., \& von Stechow, C. (2014). Annex II: Glossary. In R. K. Pachauri \& L. A. Meyer (Eds.), Climate change 2014: Synthesis report. Contribution of working groups I, II and III to the fifth assessment report of the intergovernmental panel on climate change (pp. 117-130). Geneva, Switzerland: IPCC.

Macias Fauria, M., Michaletz, S. T., \& Johnson, E. A. (2011). Predicting climate change effects on wildfires requires linking processes across scales. WIREs Climate Change, 2(1), 99-112. https://doi.org/10.1002/wcc.92

Marlon, J. R., Bartlein, P. J., Walsh, M. K., Harrison, S. P., Brown, K. J., Edwards, M. E., ... Whitlock, C. (2009). Wildfire responses to abrupt climate change in North America. Proceedings of the National Academy of Sciences, 106(8), 2519-2524. https://doi.org/10.1073/pnas.0808212106

Martin, I. M., Bender, H., \& Raish, C. (2007). What motivates individuals to protect themselves from risks: The case of wildland fires. Risk Analysis, 27(4), 887-900. https://doi.org/10.1111/j.1539-6924.2007.00930.x

Martin, W. E., Martin, I. M., \& Kent, B. (2009). The role of risk perceptions in the risk mitigation process: The case of wildfire in high risk communities. Journal of Environmental Management, 91(2), 489-498. https://doi.org/10.1016/j.jenvman.2009.09.007

Martinson, E., \& Omi, P. (2013). Fuel treatments and fire severity: A meta-analysis (Res. Pap. RMRS-RP-103WWW) (p. 38). Fort Collins, CO: U.S. Department of Agriculture, Forest Service, Rocky Mountain Research Station.

McCaffrey, S. (2004). Thinking of wildfire as a natural hazard. Society \& Natural Resources, 17(6), 509-516. https://doi.org/10.1080/08941920490452445

McCaffrey, S., \& Kumagai, Y. (2007). No need to reinvent the wheel: Applying existing social science theories to wildfire. In People, fire, and forests: A synthesis of wildfire social science (pp. 12-36). Corvallis: Oregon State University Press.

McCaffrey, S., Stidham, M., Toman, E., \& Shindler, B. (2011). Outreach programs, peer pressure, and common sense: What motivates homeowners to mitigate wildfire risk? Environmental Management, 48(3), 475-488. https://doi.org/10.1007/s00267-011-9704-6

McCaffrey, S., Wilson, R., \& Konar, A. (2017). Should I stay or should I go now? Or should I wait and see? Influences on wildfire evacuation decisions: Should I stay or should I go now? Risk Analysis, 38, 1390-1404. https://doi.org/10.1111/risa.12944

McFarlane, B. L., McGee, T. K., \& Faulkner, H. (2011). Complexity of homeowner wildfire risk mitigation: An integration of hazard theories. International Journal of Wildland Fire, 20(8), 921-931.

McGee, T. K., \& Russell, S. (2003). "It's just a natural way of life..." an investigation of wildfire preparedness in rural Australia. Global Environmental Change Part B: Environmental Hazards, 5(1), 1-12. https://doi.org/10.1016/j.hazards.2003.04.001

McLennan, J., Paton, D., \& Beatson, R. (2015). Psychological differences between south-eastern Australian householders' who intend to leave if threatened by a wildfire and those who intend to stay and defend. International Journal of Disaster Risk Reduction, 11, 35-46. https://doi.org/10.1016/j.ijdrr.2014.11.008

McPherson, M., Smith-Lovin, L., \& Cook, J. M. (2001). Birds of a feather: Homophily in social networks. Annual Review of Sociology, $27,415-444$.

Mendelsohn, R. (2000). Efficient adaptation to climate change. Climatic Change, 45(3-4), 583-600. https://doi.org/10.1023/A:1005507810350

Metz, M. R., Frangioso, K. M., Meentemeyer, R. K., \& Rizzo, D. M. (2011). Interacting disturbances: Wildfire severity affected by stage of forest disease invasion. Ecological Applications, 21(2), 313-320. https://doi.org/10.1890/10-0419.1

Millar, C. I., \& Stephenson, N. L. (2015). Temperate forest health in an era of emerging megadisturbance. Science, 349(6250), 823-826. https://doi.org/10.1126/ science.aaa9933

Millar, C. I., Stephenson, N. L., \& Stephens, S. L. (2007). Climate change and forests of the future: Managing in the face of uncertainty. Ecological Applications, 17(8), 2145-2151. https://doi.org/10.1890/06-1715.1

Monroe, M. C., \& Nelson, K. C. (2004). The value of assessing public perceptions: Wildland fire and defensible space. Applied Environmental Education and Communication, 3(2), 109-117. https://doi.org/10.1080/15330150490472781

Moritz, M. A., Batllori, E., Bradstock, R. A., Gill, A. M., Handmer, J., Hessburg, P. F., ... Syphard, A. D. (2014). Learning to coexist with wildfire. Nature, 515(7525), 58-66. https://doi.org/10.1038/nature13946

Moritz, M. A., Parisien, M.-A., Batllori, E., Krawchuk, M. A., Van Dorn, J., Ganz, D. J., \& Hayhoe, K. (2012). Climate change and disruptions to global fire activity. Ecosphere, 3(6), 1-22. https://doi.org/10.1890/ES11-00345.1

Neale, T., \& Weir, J. K. (2015). Navigating scientific uncertainty in wildfire and flood risk mitigation: A qualitative review. International Journal of Disaster Risk Reduction, 13, 255-265. https://doi.org/10.1016/j.ijdrr.2015.06.010

Nelson, D. R., Adger, W. N., \& Brown, K. (2007). Adaptation to environmental change: Contributions of a resilience framework. Annual Review of Environment and Resources, 32(1), 395-419. https://doi.org/10.1146/annurev.energy.32.051807.090348

Nelson, K. C., Monroe, M. C., \& Johnson, J. F. (2005). The look of the land: Homeowner landscape management and wildfire preparedness in Minnesota and Florida. Society \& Natural Resources, 18(4), 321-336. https://doi.org/10.1080/08941920590915233 
Nielsen-Pincus, M., Goldberg, C. S., Pocewicz, A., Force, J. E., Waits, L. P., Morgan, P., \& Vierling, L. (2010). Predicted effects of residential development on a northern Idaho landscape under alternative growth management and land protection policies. Landscape and Urban Planning, 94(3), 255-263. https://doi.org/10.1016/j.landurbplan.2009. 10.011

Niles, M. T., Brown, M., \& Dynes, R. (2016). Farmer's intended and actual adoption of climate change mitigation and adaptation strategies. Climatic Change, 135(2), 277-295. https://doi.org/10.1007/s10584-015-1558-0

North, M., Collins, B. M., \& Stephens, S. (2012). Using fire to increase the scale, benefits, and future maintenance of fuels treatments. Journal of Forestry, 110(7), 392-401. https://doi.org/10.5849/jof.12-021

North, M., Stephens, S. L., Collins, B. M., Agee, J. K., Aplet, G., Franklin, J. F., \& Fulé, P. Z. (2015). Reform forest fire management. Science, $349(6254)$, $1280-1281$. https://doi.org/10.1126/science.aab2356

Olsen, C., Kline, J., Ager, A., Olsen, K., \& Short, K. (2017). Examining the influence of biophysical conditions on wildland-urban interface homeowners' wildfire risk mitigation activities in fire-prone landscapes. Ecology and Society, 22(1), 1-21. https://doi.org/10.5751/ES-09054-220121

Orlove, B. (2005). Human adaptation to climate change: A review of three historical cases and some general perspectives. Environmental Science \& Policy, 8(6), 589-600. https://doi.org/10.1016/j.envsci.2005.06.009

Park, S. E., Marshall, N. A., Jakku, E., Dowd, A. M., Howden, S. M., Mendham, E., \& Fleming, A. (2012). Informing adaptation responses to climate change through theories of transformation. Global Environmental Change, 22(1), 115-126. https://doi.org/10.1016/j.gloenvcha.2011.10.003

Paveglio, T. B., Carroll, M. S., Hall, T. E., \& Brenkert-Smith, H. (2015). "Put the wet stuff on the hot stuff": The legacy and drivers of conflict surrounding wildfire suppression. Journal of Rural Studies, 41, 72-81. https://doi.org/10.1016/j.jrurstud.2015.07.006

Paveglio, T. B., Carroll, M. S., \& Jakes, P. J. (2010). Alternatives to evacuation during wildland fire: Exploring adaptive capacity in one Idaho community. Environmental Hazards, 9(4), 379-394. https://doi.org/10.3763/ehaz.2010.0060

Paveglio, T. B., Carroll, M. S., Stasiewicz, A. M., Williams, D. R., \& Becker, D. R. (in press). Incorporating social diversity into wildfire management: Proposing "pathways" for fire adaptation. Forest Science. https://doi.org/10.1093/forsci/fxy005

Paveglio, T. B., Edgeley, C. M., \& Stasiewicz, A. M. (2018). Assessing influences on social vulnerability to wildfire using surveys, spatial data and wildfire simulations. Journal of Environmental Management, 213, 425-439. https://doi.org/10.1016/j.jenvman.2018.02.068

Pelling, M., O'Brien, K., \& Matyas, D. (2015). Adaptation and transformation. Climatic Change, 133(1), 113-127. https://doi.org/10.1007/s10584-014-1303-0

Peter, B., \& Nelson, J. (2005). Estimating harvest schedules and profitability under the risk of fire disturbance. Canadian Journal of Forest Research; Ottawa, 35(6), 1378-1388.

Peterson, G., De Leo, G., Hellmann, J., Janssen, M., Kinzig, A., Malcolm, J., ... Tinch, R. (1997). Uncertainty, climate change, and adaptive management. Ecology and Society, 1(2), 1-4. https://doi.org/10.5751/CE-00024-010204

Polasky, S., Carpenter, S. R., Folke, C., \& Keeler, B. (2011). Decision-making under great uncertainty: Environmental management in an era of global change. Trends in Ecology \& Evolution, 26(8), 398-404. https://doi.org/10.1016/j.tree.2011.04.007

Preisler, H. K., Brillinger, D. R., Burgan, R. E., \& Benoit, J. W. (2004). Probability based models for estimation of wildfire risk. International Journal of Wildland Fire, 13(2), 133-142.

Price, D. T., Alfaro, R. I., Brown, K. J., Flannigan, M. D., Fleming, R. A., Hogg, E. H., ... Venier, L. A. (2013). Anticipating the consequences of climate change for Canada's boreal forest ecosystems. Environmental Reviews, 21(4), 322-365. https://doi.org/10.1139/er-2013-0042

Quinn-Davidson, L. N., \& Varner, J. M. (2012). Impediments to prescribed fire across agency, landscape and manager: An example from northern California. International Journal of Wildland Fire, 21(3), 210-218. https://doi.org/10.1071/WF11017

Reser, J. P., \& Swim, J. K. (2011). Adapting to and coping with the threat and impacts of climate change. American Psychologist, 66(4), 277-289. https://doi.org/10.1037/ $\mathrm{a} 0023412$

Rogers, E. (2003). Diffusion of innovations (5th ed.). New York, NY: Free Press.

Rummer, B. (2008). Assessing the cost of fuel reduction treatments: A critical review. Forest Policy and Economics, 10(6), 355-362. https://doi.org/10.1016/j.forpol. 2008.01.001

Slovic, P. (1987). Perception of risk. Science, 236(4799), 280-285. https://doi.org/10.1126/science.3563507

Slovic, P., Finucane, M. L., Peters, E., \& MacGregor, D. G. (2007). The affect heuristic. European Journal of Operational Research, 177(3), 1333-1352. https://doi.org/10.1016/ j.ejor.2005.04.006

Slovic, P., Fischhoff, B., \& Lichtenstein, S. (1982). Why study risk perception? Risk Analysis, 2(2), 83-93. https://doi.org/10.1111/j.1539-6924.1982.tb01369.x

Smit, B., Burton, I., Klein, R. J., \& Street, R. (1999). The science of adaptation: A framework for assessment. Mitigation and Adaptation Strategies for Global Change, 4(3-4), 199-213.

Smit, B., \& Skinner, M. W. (2002). Adaptation options in agriculture to climate change: A typology. Mitigation and Adaptation Strategies for Global Change, 7(1), 85-114. https://doi.org/10.1023/A:1015862228270

Smit, B., \& Wandel, J. (2006). Adaptation, adaptive capacity and vulnerability. Global Environmental Change, 16(3), 282-292. https://doi.org/10.1016/j.gloenvcha. 2006.03.008

Sober, E. (1993). The nature of selection: Evolutionary theory in philosophical focus. Chicago, IL: University of Chicago Press.

Spencer, A. G., Schultz, C. A., \& Hoffman, C. M. (2015). Enhancing adaptive capacity for restoring fire-dependent ecosystems: The fire learning Network's prescribed fire training exchanges. Ecology and Society, 20(3), 38.

Spies, T. A., White, E., Ager, A., Kline, J. D., Bolte, J. P., Platt, E. K., ... Csuti, B. (2017). Using an agent-based model to examine forest management outcomes in a fire-prone landscape in Oregon, USA. Ecology and Society, 22(1), 25. https://doi.org/10.5751/ES-08841-220125

Spittlehouse, D. L. (2005). Integrating climate change adaptation into forest management. The Forestry Chronicle, 81(5), 691-695.

Stavros, E. N., McKenzie, D., \& Larkin, N. (2014). The climate-wildfire-air quality system: Interactions and feedbacks across spatial and temporal scales. WIREs Climate Change, 5(6), 719-733. https://doi.org/10.1002/wcc.303

Stephens, S. L., Burrows, N., Buyantuyev, A., Gray, R. W., Keane, R. E., Kubian, R., ... van Wagtendonk, J. W. (2014). Temperate and boreal forest mega-fires: Characteristics and challenges. Frontiers in Ecology and the Environment, 12(2), 115-122. https://doi.org/10.1890/120332

Stephens, S. L., \& Collins, B. M. (2004). Fire regimes of mixed conifer forests in the north-Central Sierra Nevada at multiple spatial scales. Northwest Science, 78(1), $12-23$.

Swim, J., Clayton, S., Doherty, T., Gifford, R., Howard, G., Reser, J., ... Weber, E. (2009). Psychology and global climate change: Addressing a multi-faceted phenomenon and set of challenges. In A report by the American Psychological Association's task force on the interface between psychology and global climate change. Washington, DC: American Psychological Association.

Syphard, A. D., Brennan, T. J., \& Keeley, J. E. (2014). The role of defensible space for residential structure protection during wildfires. International Journal of Wildland Fire, 23(8), 1165. https://doi.org/10.1071/WF13158

Tebaldi, C., Adams-Smith, D., \& Heller, N. (2012). The heat is on: U.S. temperature trends. Climate Central. Retrieved from http://www.climatecentral.org/wgts/ heatis-on/HeatIsOnReport.pdf 
Theobald, D. M., \& Romme, W. H. (2007). Expansion of the US wildland-urban interface. Landscape and Urban Planning, 83(4), 340-354. https:// doi.org/10.1016/j.landurbplan.2007.06.002

Tibbits, A., \& Whittaker, J. (2007). Stay and defend or leave early: Policy problems and experiences during the 2003 Victorian bushfires. Environmental Hazards, 7(4), 283-290. https://doi.org/10.1016/j.envhaz.2007.08.001

Tompkins, E. L., \& Eakin, H. (2012). Managing private and public adaptation to climate change. Global Environmental Change, 22(1), 3-11. https://doi.org/10.1016/j.gloenvcha. 2011.09.010

Truelove, H. B., Carrico, A. R., \& Thabrew, L. (2015). A socio-psychological model for analyzing climate change adaptation: A case study of Sri Lankan paddy farmers. Global Environmental Change, 31, 85-97. https://doi.org/10.1016/j.gloenvcha.2014.12.010

Tschakert, P., \& Dietrich, K. A. (2010). Anticipatory learning for climate change adaptation and resilience. Ecology and Society, $15(2), 11$.

Turner, B. L., Kasperson, R. E., Matson, P. A., McCarthy, J. J., Corell, R. W., Christensen, L., ... Schiller, A. (2003). A framework for vulnerability analysis in sustainability science. Proceedings of the National Academy of Sciences, 100(14), 8074-8079. https://doi.org/10.1073/pnas.1231335100

Veblen, T. T., Kitzberger, T., \& Donnegan, J. (2000). Climatic and human influences on fire regimes in ponderosa pine forests in the Colorado front range. Ecological Applications, 10(4), 1178-1195. https://doi.org/10.1890/1051-0761(2000)010[1178:CAHIOF]2.0.CO;2

Walker, B., Holling, C. S., Carpenter, S. R., \& Kinzig, A. (2004). Resilience, adaptability and transformability in social-ecological systems. Ecology and Society, $9(2), 5$.

Watts, M. (1983). On the poverty of theory: Natural hazards research in context. In K. Hewitt (Ed.), Interpretation of calamity: From the viewpoint of human ecology (pp. 231-262). Boston, MA: Allen and Unwin.

Westerling, A. L., \& Bryant, B. P. (2007). Climate change and wildfire in California. Climatic Change, 87(1), 231-249. https://doi.org/10.1007/s10584-007-9363-z

Westerling, A. L., Bryant, B. P., Preisler, H. K., Holmes, T. P., Hidalgo, H. G., Das, T., \& Shrestha, S. R. (2011). Climate change and growth scenarios for California wildfire. Climatic Change, 109(1), 445-463. https://doi.org/10.1007/s10584-011-0329-9

Wheeler, S., Zuo, A., \& Bjornlund, H. (2013). Farmers' climate change beliefs and adaptation strategies for a water scarce future in Australia. Global Environmental Change, 23(2), 537-547. https://doi.org/10.1016/j.gloenvcha.2012.11.008

Williams, J. (2013). Exploring the onset of high-impact mega-fires through a forest land management prism. Forest Ecology and Management, 294, 4-10. https://doi.org/10.1016/j.foreco.2012.06.030

Wise, R. M., Fazey, I., Stafford Smith, M., Park, S. E., Eakin, H. C., Archer Van Garderen, E. R. M., \& Campbell, B. (2014). Reconceptualising adaptation to climate change as part of pathways of change and response. Global Environmental Change, 28, 325-336. https://doi.org/10.1016/j.gloenvcha.2013.12.002

Yue, X., Mickley, L. J., Logan, J. A., Hudman, R. C., Martin, M. V., \& Yantosca, R. M. (2015). Impact of 2050 climate change on north American wildfire: Consequences for ozone air quality. Atmospheric Chemistry and Physics, 15(17), 10033-10055. https://doi.org/10.5194/acp-15-10033-2015

Zaksek, M., \& Árvai, J. L. (2004). Toward improved communication about wildland fire: Mental models research to identify information needs for natural resource management. Risk Analysis, 24(6), 1503-1514. https://doi.org/10.1111/j.0272-4332.2004.00545.x

How to cite this article: Hamilton M, Fischer AP, Guikema SD, Keppel-Aleks G. Behavioral adaptation to climate change in wildfire-prone forests. WIREs Clim Change. 2018;9:e553. https://doi.org/10.1002/wcc.553 